\title{
Characterisation of Materials by Raman Scattering ADDENDA
}

\author{
M. KOZIELSKI* \\ Faculty of Technical Physics, Poznań University of Technology \\ Nieszawska 13A, 60-965 Poznań, Poland
}

(Received May 28, 2008)

This paper contains an erratum to [M. Kozielski, Acta Phys. Pol. A 111, 343 (2007)].

PACS numbers: 78.30.-j, 62.20.-x, 61.72.-y, 36.20.Ng

Reference [1] presents a review of the results obtained for some materials by the Raman scattering method at the Chair of Optical Spectroscopy, Poznań University of Technology. The materials included: zinc selenide ( $\mathrm{ZnSe}$ ) [2] and mixed crystals ( $\mathrm{Zn}_{1-x} \mathrm{Mg}_{x} \mathrm{Se}$ and $\mathrm{Zn}_{1-x} \mathrm{Be}_{x} \mathrm{Se}$ ) [3] obtained by the high-pressure Bridgman method, the crystals of strontium lanthanum gallate $\left(\mathrm{SrLaGaO}_{4}-\right.$ SLG) obtained by the Czochralski method [4] and the crystals of triammonium hydrogen diseleniate $\left(\left(\mathrm{NH}_{4}\right)_{3} \mathrm{H}\left(\mathrm{SeO}_{4}\right)_{2}\right.$ - TAHSe $)$ grown from water solutions [5]. Some of these results are presented and discussed in detail, among others, in the Ph.D. theses [6-8], prepared under my promotion.

Moreover, Ref. [1] contains the unpublished Fig. 8, taken from the doctoral dissertation [7], which has not been expressed in the figure caption. I would like to apologize the author of the figure for this oversight.

The author wishes once again to thank Dr. eng. M. Mühle, Dr. T. Runka and Dr. M. Szybowicz from the Chair of Optical Spectroscopy, Poznań University of Technology for cooperation in realization of experiments and Prof. Dr. hab. Z. Błaszczak from the Faculty of Physics, Adam Mickiewicz University for fruitful discussions.

*e-mail: markoz@phys.put.poznan.pl 


\section{References}

[1] M. Kozielski, Acta Phys. Pol. A 111, 343 (2007).

[2] W. Bała, F. Firszt, Z. Nowak, Proc. Conf. on Physics, Jaszowiec 1983 6, 308 (1983).

[3] J. Szatkowski, F. Firszt, H. Męczyńska, S. Łȩgowski, Acta Phys. Pol. A 84, 531 (1993).

[4] A. Pajączkowska, A. Gloubokov, Prog. Cryst. Growth Charact. 36, 123 (1998).

[5] M. Augustyniak, L. Szczepańska, Institute of Molecular Physics, Polish Academy of Science, Poznań — private information.

[6] M. Szybowicz, Ph.D. Thesis, Poznań University of Technology, Poznań 1999 (in Polish).

[7] T. Runka, Ph.D. Thesis, Poznań University of Technology, Poznań 2000 (in Polish).

[8] M. Mühle, Ph.D. Thesis, Poznań University of Technology, Poznań 2005 (in Polish). 